\title{
A Critical Evaluation of John Locke's Denial of Innatism: An Epistemological Approach
}

\author{
Ignatius Nnaemeka Onwuatuegwu ${ }^{1 *}$ and Malachi Ifeanyi Okafor $^{2}$ \\ ${ }^{1}$ Department of Philosophy, Nnamdi Azikiwe University Awka, Nigeria \\ ${ }^{2}$ Pope John Paul II Major Seminary Okpuno, Nigeria
}

Submission: August 24, 2020; Published: September 21, 2020

*Corresponding author: Ignatius Nnaemeka Onwuatuegwu, Department of Philosophy, Nnamdi Azikiwe University Awka, Nigeria

\begin{abstract}
As a rational being, man desires to know much more about himself and all around him. Since it is in the nature of man to grasp knowledge, the aim of this work is: To analyze the process of acquiring knowledge, especially how human mind can grasp knowledge. This Essay is meant to dispel skepticism in Modern minds by elucidating the possibility of knowledge. It is to show that both the empirical and rational are all sources of acquiring knowledge. That no source is more important than the other. Finally, to critically examine John Locke's position which is against innatism. To achieve the aim of this research work, the method of writing would be expository, analytical and of course critical. John Locke, in his Essay Concerning Human Understanding, laid down the foundations upon which subsequent British philosophers built their philosophy. The researcher concentrates his research on the Critique of John Locke's Denial of Innatism. The primary book that would be used for this research is An Essay Concerning Human Understanding by John Locke. Other secondary sources shall be used especially related material that would make the work clearer. The materials will be sourced from Library and internet.
\end{abstract}

Keywords: Epistemology; Scripture; Reflected light; Knowledge

\section{Introduction}

The human quest to know has really gone very far in justifying the very first statement of Aristotle in his metaphysics "All men by nature desire to know" [1]. This search has given birth to philosophy and epistemology. Epistemology is a branch of philosophy that enquires into the scope, nature, process, and sources of human knowledge. Although sometimes hidden, there is always an implicit theory of knowledge in the philosophies of different ages; each with its own peculiarity. Each era: ancient, medieval, modern, and contemporary has elements which characterized their philosophy and enquiry. Hence, from the above, one may infer that what informs the epistemology of each epoch is its concentration of man's search centered on the world, on God and on man, respectively.

As this quest for knowledge continued, there existed a particular school whose philosophical attitudes were skeptical. They believed and taught that the human mind is incapable of attaining truth. They admitted the fact that human mind is restricted from attaining the truth of things. It was really this group that triggered the search for certainty of human knowledge.

Modern philosophers were specifically occupied with the problem of human knowledge. This continued till the emergence of the celebrated work of the popular $17^{\text {th }}$ century British empiricist, John Locke. An Essay concerning Human Understanding. It was in this essay that Locke made a denial of innate idea which is the bone of contention in this research work. From 1667 to 1683, he was the personal physician and adviser to Ashley (later to become the Earl of Shaftesbury). He helped draft a constitution for the American Carolinas in 1669. Locke supported the growing demand for parliamentary right against the supremacy of the king. Locke held several important public offices. He releases a flood of writings composed during his year in exile [2].

His two most important works were Two Treatises on Government and An Essay Concerning Human Understanding, both published in 1690. Letters Concerning Toleration came out during the year 1689 to 1692 . Other works of interest were Some Thoughts Concerning Education (1693). The Reasonableness of Christianity (1695). In 1691, recurring ill health sent him into partial retirement. He moved to the Country twenty miles out of London, to seek more tranquil surroundings. Last year of his life was spent enjoying the quiet companionship of close friends and studying the scripture. There, in the home of friends he died quietly in 1704 [3]. The German thinker, Hans-Georg Gadamer has often been associated with the maxim that no one speaks from 
nowhere. This adage finds adequate expression on the issue of background to any philosophical venture. Thus, the question of historical background from time immemorial has been essential in the history of philosophy. This project came about due to the researcher's interest in the disagreement between the two philosophical camps: the rationalists and the empiricists in their search for certainty of true knowledge. In John Locke's Essay concerning Human Understanding, he made it clear that human mind is incapable of attaining true knowledge.

From the above affirmation, Locke was extremely attacking the world of Form of Plato by asserting totally that the mind is devoid of any idea when coming into the world. He boasted to explain the origin of all human knowledge through experience, thereby subscribing to empiricism. With John Locke's Essay, the gap between rationalism and empiricism was pronounced. It was his assertion that set off the interest of the researcher to make a critical evaluation on Locke's denial of innate idea. John Locke's quest for indubitable knowledge, led him to make some assertions and denials that are problematic between the empiricists and rationalists [4]. He holds that "all knowledge is acquired through experience and never innate". However, he still affirms that, human brain is tabula raza, that is to say, no idea is in the brain at birth, but all knowledge is obtained through experience.

Consequently, with Locke's stand on empiricism, the question becomes; If Locke holds that all knowledge can be attained through experience, how can some meta-empirical realities be explained? There are some characters exhibited by children before the age of cognition. How can such characters be explained empirically, given that they have not yet attained the age of cognition? These questions and many more, counteracting Locke's position, this work seeks to address.

\section{Towards Philosophical Mediation}

Locke as we have seen, gives his staunch reliance on empirical knowledge and blatantly reject all forms of belief in innate idea, with his arguments that knowledge acquired through experience are never innate in human mind. Rather, affirming that human brain is completely tabla raza at birth, fails to consider other avenues through which knowledge is acquired outside experience. Such as reason, intuition, and imagination. He even neglects that such knowledge is mathematical, geometrical and even some religious truths are possible outside experience. Hence, the researcher does not totally reject the role of experience in acquisition of knowledge but instead considers it inadequate to be the only source of knowledge as Locke imagined as there exists other avenues outside experience by which knowledge is derived and these we shall diligently proceed to explore below.

Limitations of Locke's Experience as the Ultimate Source of Knowledge
Locke believes that whatever knowledge that man has comes from experience. Nevertheless, knowledge got through experience called sense-perception has been found to be with a lot of shortcomings. Scientific findings along with discoveries have evidenced that in sense-perception; a lot of information is lost about the truth of the object being observed. If this is the case then, the knowledge through experience cannot be credited as an ultimate source of knowledge. However, the critical problem concerning sense-perception is: What kind of reality belongs to the objects that are perceived and to the organs which perceive them, and what bonds exist between these realities? Simply put, the problem is: Does my knowledge of a corporeal (physical) thing show me that thing as it is in itself? And how much does it tell me about the nature or the properties of this thing as it is in itself? To what extent can our sense perception claim objectivity?

The above questions show the difficulties in determining the exact relationship between my present sense-experience and the object represented by the experience. Therefore, it is difficult or even impossible to determine whether the subject perceives the object directly or indirectly. Whether the properties attributed to the object really belong to the object. In attempt to explain the difficulty embedded in this problem, Bertrand Russell portrays his observation of a table with respect to the effect of light beam on the colour of the table. To this he writes: Although I believe that the table is really of the same color all over the parts. The parts that reflected light look white because of the reflected light. I know that if I move, the parts that reflect light will be different so that the apparent distribution of color on the table will change. It follows that if several people are looking at the table at the same moment, no two of them will see it from exactly the same point of view and any change in the point of view makes same change in the way the light is reflected [5].

Considering Russell's illustration above, one sees that the exact colour of the table is difficult to determine since the colour of the table is something dependent on the table, the observer and the way the light falls on the table. Better still, from the nature of the problem of sense-perception and the illustrations above, we can infer that the truth about an object can either not be known as it is. Coming to the argument of illusion as against the sense data. It holds illusion as "any perceptual situation in which a physical object is actually perceived, but in which that object perceptually appears other than it really is" [6]. For example, a white wall seen in yellow light might appear to be yellow. (In such cases it is not necessary that one is deceived into believing that things are other than they are). The argument, in a radical form, aims to show the limitations in experience as the ultimate source of knowledge. It exposes the loopholes of the empiricists.

Furthermore, seen hallucination as an experience which seems exactly like a veridical perception of an ordinary object but where there is no such object there to be perceived. Like 
illusions, hallucinations in this sense do not necessarily involve deception. They are rather supposed to be merely possible events: experiences which are indistinguishable for the subject from a genuine perception of an object. For example, suppose one is now having a veridical perception of a snow-covered churchyard. The assumption that hallucinations are possible means that one could have an experience which is subjectively faint - that is, indistinguishable by the subject, "from the inside"-from a veridical perception of a snow covered churchyard, but even when there is in fact no churchyard there to be perceived [6]. This is also an inadequacy of the subject to perceive from the object. It is a flaw from the assertion of sense perception. More so, from the phenomenological point of view, it is argued that objects appear differently to different observers or differently to the same observer under different conditions. Going further to illustrate this problem, Ayer, says: That the way in which they appear is causally dependent on unnecessary factors such as the presence of light, the position of the observer, or the state of the nervous system [7].

This tries to establish that even though appearances vary, we may argue that this proves that people do not perceive sometimes, things as they really are. This accounts for, the bent nature of a stick in water against its supposed straight nature. That this is being illustrated in the domain of vision does not mean that it is only a peculiarity of visual appearance, it also occurs in the domain of other senses. The central point of this phenomenological argument according to B.O. Eboh is: There is no phenomenological difference between cases of illusion and cases of veridical perception, that is, there is no difference from the point of view of experience itself [8]. This argument somewhat proves knowledge through experience not ultimately valid.

Furthermore, a look into causal argument (one of the arguments from illusion for sense-datum theory) further potrays the weakness in the position of Locke. Thus, causal argument which is based on scientific knowledge concludes that many of our sense experiences happen appreciably far ahead than the events of which they give us knowledge. The experience being particularized here is that caused by what is visible or perceptible. This causal argument seems to suggest that perception is the result we get after a lot of things/information has dodged us. It is in the scientific language, the result we get after energy loss. This is what Hamlyn seems to suggest when he writes: It could be argued that perception is simply the experience that results from the form of energy change that affects the sense organs: this then sets up brain processes and the experience in the last stage [9].

It is nearly obvious from this argument that there is an indirect connection between experience and the object that affects the sense organ. If this is the case, what we directly perceive as the object of acquaintance cannot be the same as that about which we claim knowledge of. Better still, a look into time-lag argument can still convince us the more the inadequacy of knowledge through experience. Time-lag argument is tied with causal argument and is based on the fact that it takes time for light to travel and so there is a considerable time-lag between light leaving the objects to the moon, stars, rainbow and arriving at the human eye. Hence, the central message that this argument projects is that since it takes time for light to travel from objects to subjects, whether the time-lag is short or long, the consequence is that an event that we suppose ourselves to be witnessing took place a certain time ago. By implication of the above, what we perceive must be the result of the different caused processes, all of which take some time.

Simply put, this argument concludes that "what we see must be a sense-datum-the immediate deliverance of the senses, not the objects responsible for it" [10]. From the arguments from illusion for sense-datum theory, we can bring out the fact that we can either not know things as they really are, or that we can only have an imperfect picture of the object we claim to know. If this is the case and since these arguments lie within the ambience of sense knowledge, it follows that knowledge through experience is not the sole source of knowledge.

\section{Reason as a Source of Human Knowledge}

According to Jay Diamond in World Book, 2001, reason is defined as the mind, or an agency use in thinking. It is refers to the evidence for a belief, opinion or judgment. Better still, it refers as the process of arriving at a decision or a conclusion [11]. These fundamental truths are the causes of "reason" of all derivative facts. The kind of knowledge gotten through reason is known as apriori knowledge, which is the kind of knowledge acquired prior to or independently of experience. That reason which gives a priori principles is called "pure reason" as differentiated from practical reason. These fundamental truths are regarded as innate ideas which Locke denied. Proponents of reason as the source of knowledge believe that reason leads to episteme (knowledge), while experience leads to data (opinion). From the above, we can understand that the proponents of reason as source of knowledge believe in the existence of some ideas in the mind (innate ideas) and that through reason knowledge could be acquired.

However, in the Monadology, Leibniz writes that we reason "based on two great principles". The first of these is the principle of contradiction, which deems every contradiction to be false. Classically stated, the principle of contradiction holds that something cannot be both " $\mathrm{x}$ " and "not $\mathrm{x}$ " at the same time and in the same respect. The second great principle of reason is the principle of sufficient reason, "by virtue of which we consider that we can find no true or existent fact, no true assertion, without there being a sufficient reason why it is thus and not otherwise, although most of these reasons cannot be known to us". The classical statement of the principle of sufficient reason is nihil sine ratione: (there is nothing without reason or cause). Leibniz holds 
that every situation has an explanation, even if we must admit that we often do not have sufficient information to provide an explanation [12].

However, Descartes on his part believes that as soon as we think that we correctly perceive something, we are spontaneously convinced that it is true. Now if this conviction is so firm that it is impossible for us ever to have any reason for doubting what we are convinced of, then there are no further questions for us to ask: we have everything that we could reasonably want. For the supposition which we are making here is of a conviction so firm that it is quite incapable of being destroyed; and such a conviction is clearly the same as the most perfect certainty [6]. He simply means that our true and trusted knowledge is that which pass through reason that is our thinking. It is the only certain truth without doubt.

More still, we have intuitive knowledge which is not acquired through sense perception. Intuition refers to insights or bits of knowledge which suddenly 'pop' into consciousness as our deeper subconscious chugs away working on data that we have collected earlier. We have all probably had the experience where the answer to a question we were previously thinking about but have currently forgotten has suddenly popped into our minds for no reason. This is intuition and, as such, like reason, it too is dependent on our senses to provide the raw material on which the subconscious works. Sometimes intuition seems to be a 'feeling'. We often say something like "I have the feeling he's not telling the truth," without being sure of why. The psychologist Jung suggested that actually this is actually a form of unconscious reasoning where your subconscious picks up on the tell-tale signs of lying (sweating, nervous movements, etc) that are too subtle for your conscious mind to notice and processes them resulting in the 'feeling' that this person is untrustworthy [13].

Admittedly, other people are continual sources of information. Such information, however, is always second-hand knowledge - or third-, fourth-hand knowledge. It is all "hearsay." The farther it is removed from our own personal experience, the more caution we must exercise before accepting a fact-claim. All our historical knowledge is acquired in this way as is most of our knowledge of the sciences. We cannot experience the past or personally repeat every experiment, so we must trust the specialists and accept, though not blindly, the discoveries they record for us. The key thing with knowledge from authority is that it can be doublechecked and the work of scientists and historians is continually being 'double checked' as other workers in the same field (even sometimes us in our classrooms) repeat their experiments or investigations [13].

Perhaps, we have revealed knowledge; it is more of religious belief. It is the knowledge disclosed to man especially by God without any empirical aid. At certain time in the history of man,
God inspired certain individuals to write down truths so that other people can know those truths [14]. Thus, from the foregoing, it is clear that certain truth (knowledge) are derived from reason, intuition, authority and even religion outside experience as Locke denied, yet reason alone is not to be considered as the ultimate source of knowledge.

\section{A Philosophical Mediation}

Having considered the contents of each of the faculties, reason and experience, their credits as well as their shortcomings, none of them can be considered as the sole source of human knowledge. None of them can be regarded as one which has or can totally attain the truth of things or reality of the universe. While the rationalists' emphasis on reason points to what is peculiar only to man's intellectual knowledge, the empiricists' emphasis on experience points to what man shares with other animals - sense knowledge. In order to attain true knowledge, to establish true source of knowledge, there is the need to strike a balance between the views of rationalism and empiricism, because each contains what makes up the human entity- reason or sensation. Kant tried to strike this balance by his mediation between the rationalists and the empiricists. Kant holds that the rationalists and the empiricists are both partially correct in their view that human knowledge comes from reason and the senses, respectively. The raw materials of knowledge are received by us in the form of sensation which we get from an outside source, hence in sensation we are passive. On the other hand, we are active in thought since thought consists of a spontaneous operation of the mind on the materials sensation feeds the mind with. From this, it is clear that knowledge is neither the effort of the subject nor of the object; true knowledge cannot be gained either rationally alone or empirically alone, but it can be gained by the synthesis of the continued action of the subject and the object, sensation and thought. When the subject provides the form and the object provides the matter, knowledge is gained, and this knowledge becomes the result of a priori element, (the subject) and of a synthetic element (the object).

Adopting the terms of Kant, the object is perceived through the a priori forms of perception- space and time. Space and time are the condition sine qua non for our perceiving the object, for the mind imposes these forms on the object for them to be perceived. Without them, we cannot perceive the object. Space and time are the form of our perceptive facility, the contribution of the subject. And it is only in space and time that an object like tree is perceived. Without space and time, the object cannot be perceived. They are the pre-conditional modes which the mind imposes on the object; hence in line with the philosophical principle that whatever is received is received according to the mode of the receiver: Quid recipitor and modum recipientis recipitor. So, from this, we can make out the fact that the cognition of space and time is the prior condition of the cognition of object. The cognition 
of objects is experience and the cognition of space and time is prior to all experience since space and time are the conditions of all experiences. This is where the problem of rationalism and empiricism lies. Both need the other to attain knowledge since our mind must necessarily impose the concepts of space and time on things for that thing to be perceived. Lawhead commenting on Kant's mediation says "For sense data to be experienced as object by us, the mind must impose a certain rational structure on them" [3]. These rational structures which the mind imposes on the object in this case are space and time. Space and time do not exist apart from us, but they are simply our way of perceiving things.

\section{Summary of Findings}

Thus, Locke as we have seen accounting for the origin of human knowledge places experience at the epicenter and denies that there is any possible means by which knowledge is derived outside this [4]. Hence the claims to innate ideas by Plato and other rationalists are simply elusive to Locke. However, Locke's position is weakened with the consideration that mere experience does not fully account for all our knowledge as there exists other avenues outside experience by which knowledge is acquired. Thus, such knowledge gotten through reason does not necessarily need experience to prove them. Here with reason both abstract and meta-physical knowledge is harnessed. Also, Locke fails to consider that even such knowledge gotten through experience is imbued with many shortcomings and therefore, not reliable to be the only source of human knowledge [15].

This is supported with the scientific discoveries that in senseperceptions; a lot of information is lost about the truth of the object being observed. Thus, such cases as a mirage and the seemingly blue color of a river when viewed from afar immediately stands to dismiss Locke's reliance on experience as the ultimate source of human knowledge. For here even the experience becomes deceptive. More so, Locke insistence on experience as the only source of human knowledge, fails to take account of the fact that such knowledge as mathematical knowledge, geometrical knowledge and even religious knowledge often need no experience for its acquisitions and this disproof's experience to exists as the only source of human knowledge as Locke had insisted [16].

Therefore, Locke's epistemology is not wholly accepted. As there exists, no doubt, some contradictions, and inconsistencies in his denial of innatism. He holds for instance that the mind cannot have a greater certainty than that attained in intuition. As it were, intuition is the ability to know something by using one's feelings instead of considering facts. It goes with one is feeling and reasoning. In other words, it is spontaneous and unconscious. When it is not put in action, we may lose the knowledge we could have gained from it. Since our experience should be immediate and not mediate, the use of intuition counteracts the empiricist's stand that all knowledge comes from experience. However, the Lockean proposition of experience as a source of human knowledge is not wholly to be rejected but rather its complete reliance on experience alone to be the source of human knowledge.

This is because experience provides, no doubt, some knowledge of objects. But does not account for all human knowledge. Thus, with the strength of the foregoing and in order to fully account for all our knowledge, there arises the need to recognize the role of both experience, reasons and intuition as opposed to Locke, who imagines experience only to be the source of human knowledge.

\section{Conclusion}

The impact of this study lies in the fact that it will make present what has been written and discussed many centuries ago. More explicitly: One can learn that true knowledge can only be achieved through critique and dialogue, makes us to know that all knowledge does not come from experience alone or originally from the mind alone but from the two. Reason and experience are needed for the realization of truth. This study will enable people not to believe without understanding.

\section{References}

1. McKeon R (1941) The Basic Works of Aristotle. University of North Carolina At Chapel Hill, Random House New York p. 689.

2. Campbell A (1937) Great Book of the World Encyclopedia British. Oxford University p. 95.

3. Lawhead W (2002) The Voyage of Discovery. A Historical Introduction of Philosophy $2^{\text {nd }}$ edition, Wadsworth Group, p. 273.

4. Omoregbe J (1998) Epistemology (Theory of Knowledge). A Systematic and Historical Study, Ikorodu road Maryland, Joja Press, Lagos, p. 85.

5. Russell B (1972) The Problem of Philosophy. Oxford University Press, Oxford, p. 2.

6. Stanford Encyclopedia of Philosophy (2017) Problem of Perception.

7. Ayer AJ (1995) The Problem of Knowledge in B O Eboh Theory of Knowledge. Fulladu Publishing Company, Nsukka, p. 29.

8. Eboh BO (1995) The Theory of Knowledge. Fulladu Publishing Company, Nsukka, p. 30

9. Hamlyn DW (1995) The Theory of Knowledge in B. O. Eboh Theory of Knowledge. Fulladu Publishing Company, Nsukka, p. 30.

10. Edwards (1995) A Modern Introduction to Philosophy. Quoted in B. O. Eboh, Theory of Knowledge, Fulladu Publishing Company, Nsukka, p. 31.

11. Diamond J (1993) The World Book Encyclopedia. A Scott Fetzer Company Chicago, American, p.173.

12. Leibniz GW (1990) Discourse on Metaphysics and Related Writings. Edited and translated by Martin RND and Stuart, Manchester University Press.

13. Source of Knowledge (2017).

14. Ezeani GI (2009) Fundamental of Philosophy and Logic. $1^{\text {st }}$ edition, J. Jacob's Classic Publisher Ltd, New IMT road by Mkpokiti, Enugu, p. 38.

15. Encyclopedia of Philosophy. Descartes Epistemology.

16. Stumpf E (1971) Philosophy: History and Problem. $6^{\text {th }}$ edition, pp. 251252. 


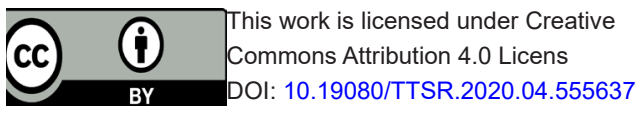

\begin{tabular}{|l|}
\hline \multicolumn{1}{|c|}{ Your next submill reach you the below assets } \\
- Quality Editorial service \\
- Swift Peer Review \\
- Reprints availability \\
- E-prints Service \\
- Manuscript Podcast for convenient understanding \\
- Global attainment for your research \\
- Manuscript accessibility in different formats \\
( Pdf, E-pub, Full Text, Audio) \\
- Unceasing customer service \\
Track the below URL for one-step submission \\
https://juniperpublishers.com/online-submission.php \\
\hline
\end{tabular}

